\title{
AVALIAÇÃO DOS PARÂMETROS FÍSICO-QUÍMICOS DO LEITE 'IN NATURA' COMERCIALIZADO INFORMALMENTE NO MUNICÍPIO DE CALÇADO - PE SOB EFEITO DE DIFERENTES TEMPERATURAS
}

\section{EVALUATION OF PHYSICOCHEMICAL PARAMETERS OF THE MILK 'IN NATURE' FROM INFORMAL COMMERCE IN THE CITY OF CALÇADO- PE IN RESPONSE TO DIFFERENT TEMPERATURES}

João Rufino de Freitas Filho ${ }^{1}$, João Sales de Souza Filho², Adriano Henrique Izidoro da Silva ${ }^{3}$, Heraldo Bezerra de Oliveira ${ }^{4}$, Janieire Dorlamis Cordeiro Bezerra ${ }^{4}$, Jucleiton José Rufino de Freitas ${ }^{5}$

\author{
1,2,4,5 Universidade Federal Rural de Pernambuco - UFRPE - Garanhuns - Brasil \\ joaoveronice@yahoo.com.br \\ ${ }^{3}$ Escola Dom João da Mata Amaral - Garanhuns - Brasil
}

\begin{abstract}
Resumo
O objetivo do trabalho foi avaliar os parâmetros físico-químicas do leite "in natura" comercializado informalmente na cidade de Calçado-PE sob efeito de diferentes temperaturas. As amostras foram coletadas em pequenas propriedades rurais de Calçado- PE, entre os meses de agosto a dezembro de 2009. Foram avaliados os parâmetros físico-químicos das amostras após serem submetidas aos tratamentos: leite in natura à temperatura ambiente (T1); após fervura (T2); após refrigeração, a $10^{\circ} \mathrm{C}$, por $48 \mathrm{~h}$ (T3) e após congelamento por sete dias (T4). Os valores médios de densidade apresentaram-se abaixo e acima dos limites recomendados, nos diferentes tratamentos. Com relação à acidez titulável, as amostras excederam os valores. O leite "in natura", armazenado em geladeira, favoreceu o crescimento de bactérias e o processo de fervura proporcionou redução das bactérias do leite. Evidenciou-se que as qualidades físico-químicas estão principalmente ligadas às práticas de manejo durante a ordenha.
\end{abstract}

Palavras-chave: Leite "in natura”, parâmetros físico-químico, temperatura.

\section{Introdução}

O leite é considerado um alimento muito nutritivo e de fácil assimilação. Por esta razão, torna-se um alimento adequado para o homem e também um bom meio de cultura para a maioria dos microrganismos (SILVEIRA et al., 1989; BRANDÃO, 1999). O manejo higiênico sanitário nas propriedades leiteiras, as estações do ano, o estresse dos animais e a fase de lactação são fatores que 
podem alterar a qualidade do leite. Neste sentido, os parâmetros físico-químicos e microbiológicos do leite têm sido ferramentas importantes na avaliação da qualidade do leite pelos órgãos governamentais e pela indústria leiteira.

Os mercados nacionais e internacionais são sem dúvida o fator motivador geral que estimula o Brasil a discutir pagamento por qualidade (MARTINS et al., 2004). Segundo Souza et al. (1995) o leite é fonte alimentar de proteínas de alto valor biológico, vitaminas e minerais, porém a sua composição química o torna um alimento altamente perecível e as suas características físicas, químicas e biológicas são facilmente alteradas pela manipulação, crescimento de vários grupos de microrganismos desejáveis e indesejáveis. A presença e multiplicação de microrganismos provocam alterações físico-químicas no leite, o que limita sua durabilidade. Os parâmetros físico-químicos do leite podem ser alterados em função de alguns fatores nutricionais, ambientais (SANTOS et al., 1981), fraudes do produto (PADILHA e FERNANDEZ, 1999), dentre outros. Fagan et al. (2008) descreve em seu trabalho que as qualidades físico-químicas e microbiológicas estão principalmente ligadas às práticas de manejo durante a ordenha.

A qualidade físico-química visa avaliar o valor alimentar ou rendimento industrial e ainda detectar possíveis fraudes. A qualidade do leite depende de programas específicos que contemplem os diversos fatores que podem influenciar na composição físico-química, microbiológica e celular. Daí, a maior parte dos países tem buscado executar programas de pagamento por qualidade, baseando-se no nível de contaminação microbiana, teores de gordura, de sólidos não gordurosos, presença de inibidores e outros parâmetros (MENDONÇA et al., 2001).

A análise da composição físico-química do leite é importante, pois também é considerada, junto às analises microbiológicas, parâmetros de qualidade do leite, possibilitando estabelecer, dessa forma um critério de pagamento ao produtor (TEIXEIRA,1998).

No Brasil, práticas inadequadas de produção e manuseio do leite nas propriedades, elevada temperatura ambiente, enorme distância entre a propriedade e o local de processamento, entre outras, tornam o leite de baixa qualidade (ROSSI et al., 1992). O sistema ideal de conservação do leite é a refrigeração, entretanto, soluções desse tipo nem sempre são viáveis, por razões de ordem técnica e econômica (ROSSI et al., 1994).

As maiores preocupações quanto à qualidade físico-química do leite estão associadas ao estado de conservação, à eficiência do seu tratamento térmico e integridade físico-química, principalmente aquela relacionada à adição ou remoção de substâncias químicas próprias ou estranhas à sua composição (POLEGATO e RUDGE, 2003). Segundo dados encontrados na literatura (AGNESE, 2002; DONATELE et al., 2003; VIEIRA e CARVALHO, 2003), a avaliação da qualidade do leite, levando-se em conta o parâmetro acidez, por meio da determinação de pH, 
titulação através do grau Dornic e teste de Alizarol, vem sendo bastante utilizada nos laticínios e testada por alguns pesquisadores, devido à facilidade e rapidez na sua execução.

Segundo Nero et al. (2005), a adoção do resfriamento do leite nas propriedades e a granelização da coleta são importantes medidas para melhorar a qualidade microbiológica do leite. No entanto, a refrigeração por períodos prolongados pode comprometer a qualidade do leite cru, devido à possibilidade de seleção de bactérias psicrotróficas proteolíticas. Por essa razão são necessários investimentos contínuos em boas práticas para prevenção do crescimento microbiano na cadeia produtiva do leite, para reduzir problemas tecnológicos e econômicos na indústria de laticínios (PINTO et al., 2006).

De acordo com o Regulamento Técnico de Identidade e Qualidade do Leite Cru Refrigerado da Instrução Normativa 51 (BRASIL, 2002), já implantada desde junho de 2005, o leite cru refrigerado deverá atender a Contagem de Células Somáticas (CCS) e os padrões físico-químicos de: gordura, densidade relativa, acidez titulável, extrato seco desengordurado, índice crioscópico e proteína. Segundo Mattos e Pedroso (2005), os valores exigidos pela IN 51 são os mínimos aceitáveis para melhoria da matéria-prima. À medida que os laticínios passarem a remunerar o produtor pela qualidade os valores exigidos pela legislação serão gradativamente alterados para melhorar a qualidade do leite.

Este trabalho teve como objetivo avaliar os parãmetros físico-químicas do leite "in natura" comercializado informalmente em diferentes pontos na cidade de Calçado - PE sob efeito de diferentes temperaturas.

\section{Material e Métodos}

\section{Coleta de amostras}

Foram coletadas amostras de leite "in natura" às 9:00h da manhã, em nove propriedades rurais, localizados em na cidade de Calçado - PE, no período de agosto a dezembro de 2009. As amostras $(1000 \mathrm{~mL})$ foram acondicionadas em caixa de isopor com gelo e enviadas ao Laboratório de Ensino de Química Orgânica da Universidade Federal Rural de Pernambuco/Unidade Acadêmica de Garanhuns, para análise imediata. Cada amostra foi fracionada em subamostras, e esssas submetidas aos seguintes tratamentos:

a) leite "in natura" a temperatura ambiente (T1);

b) leite "in natura" após fervura (T2);

c) leite "in natura" após refrigeração, a $10^{\circ} \mathrm{C}$, por $48 \mathrm{~h}$ (T3) e 
d) leite "in natura" após congelamento por sete dias.

\section{Condições das propriedades}

Das nove propriedades rurais estudadas, todas estavam produzindo leite no período da pesquisa e realizavam a ordenha em curral de chão batido. Nenhuma propriedade dispunha de sala de ordenha e de água disponível no curral, o que limitava o atendimento de alguns dos requisitos da IN no 51, de 19/9/2002, do Ministério de Estado da Agricultura, Pecuária e Abastecimento, a qual aperfeiçoa a legislação sanitária federal sobre a produção deleite. Ressalta-se que a referida Instrução define os regulamentos técnicos de produção, transporte, identidade e qualidade do leite.

O sistema de ordenha em todas as propriedades estudadas era o manual, com bezerro ao pé, realizado uma vez ao dia, no período de 5:00 às 6:30 da manhã.

\section{Método de análises}

\section{Análises físico-químicas}

Os parâmetros físico-químicos avaliados foram os seguintes:

a) acidez titulável, pela titulação de hidróxido de sódio $0,1 \mathrm{~N}$ com indicador fenolftaleína $(1 \%)$

b) $\mathrm{pH}$, obtido utilizando pHmetro (Marconi);

c) Densidade, gordura e proteínas, determinadas segundo metodologia proposta por Freitas Filho et al. (2009).

Todas as análises foram realizadas em triplicata.

\section{Resultados e Discussão}

As amostras foram adquiridas em pequenas propriedades da cidade de Calçado - PE e em seguida analisadas obedecendo aos métodos analíticos oficiais exigidos pelo Ministério da Agricultura. Nas 09 amostras analisadas, os resultados estão sumarizados na tabela 1.

Entre as características físico-químicas do leite, relatadas na literatura, as alterações que ocorrem em relação ao $\mathrm{pH}$, são as mais pronunciadas, principalmente em relação à qualidade microbiológica do leite (FONSECA e SANTOS, 2000). 
Tabela 1 - Resultados (média \pm desvio-padrão) de pH, acidez, gordura (G), proteína do leite "in natura" após diferentes tratamentos

\begin{tabular}{|c|c|c|c|c|c|}
\hline \multirow[t]{2}{*}{ FAZENDA } & \multirow[t]{2}{*}{ VARIÁVEL } & \multicolumn{3}{|c|}{ TRATAMENTO } & \multirow[b]{2}{*}{$\mathbf{T 4}$} \\
\hline & & T1 & $\mathbf{T 2}$ & T3 & \\
\hline \multirow{5}{*}{ A1 } & $\mathrm{pH}$ & $6,64 \pm 0,01$ & $6,57 \pm 0,03$ & $6,63 \pm 0,01$ & $6,49 \pm 0,01$ \\
\hline & Acidez & $27,0 \pm 1,00$ & $25,7 \pm 0,60$ & $32,7 \pm 1,00$ & $23,0 \pm 1,00$ \\
\hline & densidade & $1,032 \pm 0,00$ & $1,034 \pm 0,00$ & $1,032 \pm 0,00$ & $1,028 \pm 0,00$ \\
\hline & Gordura & $3,74 \pm 0,15$ & $3,42 \pm 0,20$ & $3,93 \pm 0,07$ & $3,98 \pm 0,03$ \\
\hline & Proteína & $4,06 \pm 0,07$ & $3,88 \pm 0,08$ & $3,99 \pm 0,14$ & $3,89 \pm 0,03$ \\
\hline \multirow{5}{*}{ A2 } & $\mathrm{pH}$ & $6,68 \pm 0,01$ & $6,60 \pm 0,02$ & $6,67 \pm 0,01$ & $6,56 \pm 0,01$ \\
\hline & Acidez & $34,7 \pm 0,60$ & $28,7 \pm 1,00$ & $31,7 \pm 1,00$ & $24,3 \pm 0,60$ \\
\hline & densidade & $1,041 \pm 0,00$ & $1,044 \pm 0,00$ & $1,041 \pm 0,00$ & $1,049 \pm 0,00$ \\
\hline & Gordura & $3,88 \pm 0,15$ & $3,37 \pm 0,20$ & $3,98 \pm 0,21$ & $4,19 \pm 0,16$ \\
\hline & Proteína & $3,99 \pm 0,07$ & $3,61 \pm 0,11$ & $3,97 \pm 0,09$ & $3,90 \pm 0,16$ \\
\hline \multirow{5}{*}{ A3 } & $\mathrm{pH}$ & $6,53 \pm 0,01$ & $6,47 \pm 0,01$ & $6,50 \pm 0,01$ & $6,41 \pm 0,01$ \\
\hline & Acidez & $34,3 \pm 1,00$ & $33,7 \pm 0,60$ & $36,3 \pm 1,00$ & $28,3 \pm 0,60$ \\
\hline & densidade & $1,032 \pm 0,00$ & $1,034 \pm 0,00$ & $1,032 \pm 0,00$ & $1,029 \pm 0,00$ \\
\hline & Gordura & $3,82 \pm 0,12$ & $3,42 \pm 0,16$ & $4,34 \pm 0,18$ & $4,21 \pm 0,19$ \\
\hline & Proteína & $3,90 \pm 0,07$ & $3,43 \pm 0,11$ & $3,70 \pm 0,21$ & $3,92 \pm 0,04$ \\
\hline \multirow{5}{*}{ A4 } & $\mathrm{pH}$ & $6,69 \pm 0,01$ & $6,63 \pm 0,02$ & $6,67 \pm 0,01$ & $6,60 \pm 0,01$ \\
\hline & Acidez & $28,3 \pm 0,60$ & $26,0 \pm 1,00$ & $30,0 \pm 1,00$ & $23,7 \pm 1,00$ \\
\hline & densidade & $1,017 \pm 0,00$ & $1,024 \pm 0,00$ & $1,023 \pm 0,00$ & $1,008 \pm 0,00$ \\
\hline & Gordura & $3,35 \pm 0,15$ & $3,01 \pm 0,20$ & $4,08 \pm 0,25$ & $4,16 \pm 0,07$ \\
\hline & Proteína & $3,97 \pm 0,06$ & $3,51 \pm 0,13$ & $3,87 \pm 0,13$ & $3,69 \pm 0,19$ \\
\hline \multirow{5}{*}{ A5 } & $\mathrm{pH}$ & $6,71 \pm 0,02$ & $6,64 \pm 0,01$ & $6,66 \pm 0,01$ & $6,59 \pm 0,01$ \\
\hline & Acidez & $28,7 \pm 0,90$ & $25,3 \pm 0,60$ & $30,3 \pm 0,60$ & $20,0 \pm 1,00$ \\
\hline & densidade & $1,014 \pm 0,00$ & $1,023 \pm 0,00$ & $1,016 \pm 0,00$ & $1,011 \pm 0,00$ \\
\hline & Gordura & $4,03 \pm 0,08$ & $3,77 \pm 0,31$ & $4,19 \pm 0,14$ & $4,06 \pm 0,10$ \\
\hline & Proteína & $3,81 \pm 0,19$ & $3,57 \pm 0,25$ & $3,81 \pm 0,12$ & $3,91 \pm 0,09$ \\
\hline \multirow{5}{*}{ A6 } & $\mathrm{pH}$ & $6,10 \pm 0,06$ & $5,90 \pm 0,00$ & $6,03 \pm 0,03$ & $6,09 \pm 0,03$ \\
\hline & Acidez & $30,3 \pm 0,60$ & $24,6 \pm 0,60$ & $31,3 \pm 0,60$ & $9,70 \pm 0,50$ \\
\hline & densidade & $0,994 \pm 0,02$ & $1,032 \pm 0,01$ & $1,044 \pm 0,01$ & $1,056 \pm 0,03$ \\
\hline & Gordura & $3,89 \pm 0,21$ & $3,02 \pm 0,15$ & $3,55 \pm 0,15$ & $3,98 \pm 0,13$ \\
\hline & Proteína & $2,90 \pm 0,21$ & $2,97 \pm 0,25$ & $2,79 \pm 0,28$ & $3,13 \pm 0,11$ \\
\hline \multirow{5}{*}{ A7 } & $\mathrm{pH}$ & $6,70 \pm 0,06$ & $6,50 \pm 0,01$ & $6,27 \pm 0,00$ & $6,25 \pm 0,01$ \\
\hline & Acidez & $25,6 \pm 1,00$ & $19,3 \pm 0,60$ & $19,7 \pm 0,60$ & $5,50 \pm 0,06$ \\
\hline & densidade & $0,942 \pm 0,01$ & $0,982 \pm 0,01$ & $1,024 \pm 0,00$ & $1,055 \pm 0,02$ \\
\hline & Gordura & $3,19 \pm 0,06$ & $3,14 \pm 0,12$ & $2,08 \pm 0,26$ & $2,77 \pm 0,07$ \\
\hline & Proteína & $2,45 \pm 0,08$ & $2,18 \pm 0,30$ & $2,67 \pm 0,12$ & $1,95 \pm 0,08$ \\
\hline \multirow{5}{*}{ A8 } & $\mathrm{pH}$ & $6,50 \pm 0,01$ & $6,20 \pm 0,06$ & $6,40 \pm 0,26$ & $6,30 \pm 0,09$ \\
\hline & Acidez & $25,0 \pm 0,58$ & $20,0 \pm 0,00$ & $20,0 \pm 0,00$ & $5,00 \pm 0,01$ \\
\hline & densidade & $1,040 \pm 0,02$ & $0,935 \pm 0,02$ & $1,023 \pm 0,00$ & $1,065 \pm 0,01$ \\
\hline & Gordura & $2,61 \pm 0,01$ & $2,48 \pm 0,21$ & $2,48 \pm 0,25$ & $2,35 \pm 0,10$ \\
\hline & Proteína & $3,22 \pm 0,26$ & $2,60 \pm 0,15$ & $3,58 \pm 0,52$ & $3,80 \pm 0,35$ \\
\hline \multirow{5}{*}{ A9 } & $\mathrm{pH}$ & $6,50 \pm 0,06$ & $6,10 \pm 0,05$ & $6,51 \pm 0,02$ & $6,36 \pm 0,05$ \\
\hline & Acidez & $30,0 \pm 0,60$ & $24,0 \pm 0,40$ & $30,0 \pm 0,60$ & $5,0 \mathrm{o} \pm 0,58$ \\
\hline & densidade & $0,966 \pm 0,05$ & $0,980 \pm 0,06$ & $1,014 \pm 0,01$ & $1,112 \pm 0,02$ \\
\hline & Gordura & $3,27 \pm 0,21$ & $3,15 \pm 0,12$ & $3,64 \pm 0,12$ & $2,84 \pm 0,13$ \\
\hline & Proteína & $2,76 \pm 0,08$ & $2,65 \pm 0,25$ & $3,83 \pm 0,18$ & $3,91 \pm 0,09$ \\
\hline
\end{tabular}

$\mathrm{T} 1$ - leite in natura à temperatura ambiente; T2 - leite in natura após fervura; T3 - leite in natura refrigerado, mantido a $10^{\circ} \mathrm{C}$, por $48 \mathrm{~h} ; \mathrm{T} 4$ - leite in natura congelado por 7 dias.

De acordo com dados da tabela 1, os valores de $\mathrm{pH}$ para as amostras das propriedades $\mathbf{A 1}, \mathbf{A 2}$, A3, A4 e A5 estão dentro da faixa ideal, ou seja, os valores de $\mathrm{pH}$ do leite normal ficam entre 6,43 a 6,82 e é um indicador da qualidade sanitária e da estabilidade térmica do leite. A amostra da propriedade A6 encontra abaixo do exigido e indica a presença de colostro. As amostra A7, A8 e A9 apresentaram valores inferiores aos exigidos em diferentes tratamentos, por exemplos, a amostra 
da propriedade A7 apresentou valores inferiores no tratamento 3 e 4; a amostra da propriedade A8, no tratamento T2, T3 e T4 e a amostra A9 no tratamento T2 e T4.

Vários pesquisadores (AGNESE, 2002; DONATELE et al., 2003; OLIVEIRA et al., 2003) têm avaliado as características físico-químicas de amostras de leites crus e pasteurizados comercializadas em diversos estados do nordeste, utilizando os parâmetros de acidez em graus Dornic e o teste de alizarol como indicativos de qualidade.

O parâmetro acidez foi avaliado por meio de titulação através de graus Dornic e todas as amostras apresentaram resultados fora dos padrões exigidos pela legislação, que preconiza limite de 0,14 a 0,18g de ácido láctico/100 mL (BRASIL, 2002). Nas propriedades A6, A7, A8, A9, no tratamento 4 a acidez em graus Dornic apresentou valores inferiores ao exigidos e nos outros tratamentos (T1, T2, T3) apresentaram valores superiores. A baixa acidez em algumas amostras pode estar relacionada aos valores do IC, pois o volume de água adicionado leva à redução proporcional nos valores de acidez (RODRIGUES et al., 1995). Nas propriedades A1, A2, A3, A4 e A5 a acidez Dornic foi superior em todos os tratamentos. Esse comportamento pode ser explicado por possíveis faltas de higiene na ordenha, doença inflamatória nas glândulas mamárias e ordenha manual. Possivelmente, alguns animais tinham inflamações nas glândulas mamárias, pois o leite entregue para análise apresentou amostras com grumos filamentosos. Segundo Oliveira et al. (2003), a acidez elevada no leite pode ser resultado da acidificação da lactose, provocada pela multiplicação de microrganismos deterioradores e/ou patogênicos.

A densidade do leite deve apresentar-se entre 1,028 e 1,034, segundo recomendação da legislação vigente (BRASIL, 2002). Valores abaixo dessa faixa podem indicar adição de água, e valores acima, fraude por adição de outras substâncias ou desnate do leite (POLEGATO e RUDGE, 2003). De acordo com os resultados sumarizados na tabela 1 , nota-se que $22,5 \%$ das amostras de leite apresentaram abaixo da faixa, 22,5 apresentaram valores dentro do limite estabelecido pela legislação e 55\% apresentaram valores inferiores ou superiores dependendo do tratamento submetido. As amostras das propriedades A6, A7, A8 e A9, os valores estimados para densidade no tratamento 4 foram superiores ao exigido. Já no tratamento 1 as amostras das propriedades A6, A7 e A9 apresentaram valores inferiores.

Estes valores são semelhantes aos obtidos por Freitas et al. (1995), que detectaram 60,6\% de amostras na faixa regulamentar e 39,4\% abaixo da mesma. Os valores inferiores de densidade observados nas amostras das propriedades A6, $\mathbf{A 7}$ e $\mathbf{A 9}$ provavelmente estão relacionados à fraude por adição de água detectada nas mesmas.

Os valores médios de teor de gordura nas amostras das propriedades A7 (tratamento 3 e 4), A8 (tratamento 1, 2, 3 e 4) e A9 (tratamento 4) estavam abaixo do mínimo aceitável, ou seja, 
$2,08 \%$ a 2,84\%. Existem diversos fatores que podem afetar a porcentagem de gordura no leite, tais como, estágio de lactação ou ordem de lactação no dia (PEREIRA et al., 1993), ou desnate.

Dentre os parâmetros físico-químicos de qualidade, a proteína do leite é um dos mais importantes, principalmente para a indústria, em decorrência de sua relação com o rendimento industrial. Os resultados para o teor de proteína no leite estão apresentados na Tabela 1. É possível verificar a variação do teor nas diferentes propriedades e nos tratamentos submetidos. Estes valores variam de 1,97 a 4,06 .

Pesquisas revelam que o leite, mesmo sob refrigeração, permite o crescimento, a produção e a atividade de proteases bacterianas. Adams et al. (1976) detectaram degradação da א-caseína antes de a população bacteriana atingir $104 \mathrm{UFC} / \mathrm{mL}$. A $\beta$-caseína foi mais degradada que a $\alpha$-caseína. Alguns psicrotróficos (cepas de Pseudomonas) também degradaram as proteínas do soro

Embora a quantidade de proteína seja importante para o rendimento industrial, existe também uma preocupação com a qualidade de proteína presente no leite. Observa-se redução nos teores de proteína do leite para todas as amostras das propriedades quando o leite passou pelo processo de fervura. Estes resultados podem indicar uma ligação direta entre perdas por desnaturação de proteínas quando o leite de má qualidade é aquecido termicamente.

Segundo Santos et al. (2009), a estocagem do leite "in natura" refrigerado por períodos maiores que 48 horas é preocupante, pois reflete negativamente na qualidade do leite "in natura" refrigerado. Isto pode-se perceber no nosso experimento quando o leite foi submetido a refrigeração no tempo descrito acima, pois houve decréscimo no teor de gordura e acidez titulável e um aumento significante no valor da densidade.

De modo geral, o leite é obtido sob condições higiênico-sanitárias deficientes e, consequentemente, apresenta elevado número de microrganismo, o que constitui um risco à saúde da população brasileira, principalmente quando consumido sem tratamento térmico. Evidentemente que o leite produzido nacionalmente nem sempre apresenta qualidade desejada, mas tem gerado discussão e desenvolvimento de novas políticas de incentivo à produção leiteira, como o Programa Nacional de Melhoria da Qualidade do Leite (NERO et al., 2005). De acordo com Alvin e Martins (2003), as mudanças impostas à pecuária leiteira nacional fizeram com que um novo perfil se desenhasse para o setor, pois o estímulo à melhoria da qualidade, além de valorizar o produto em si, traz também ganhos pelo aumento de produtividade. Nesse sentido, a produção e o processamento de leite de alta qualidade trazem benefícios tanto para os produtores quanto para a indústria e os consumidores, o que é importante para garantir a confiança do consumidor e a competitividade da cadeia produtiva do leite. 


\title{
4 Conclusão
}

Observou-se que o leite "in natura" comercializado em Calçado - PE apresenta, em geral, algumas irregularidades nos parâmetros exigidos em seus regulamentos técnicos, sugerindo faltas de higiene na ordenha, doença inflamatória nas glândulas mamárias e ordenha que era feita manualmente. Possivelmente, alguns animais tinham inflamações nas glândulas mamárias, pois o leite entregue para análise, apresentou amostras com grumos filamentosos. Outro fator que pode ter contribuído para a má qualidade do leite foi o tempo que o mesmo passou sem ser refrigerado - da ordenha até o momento de entrega do leite aos pesquisadores.

A fervura doméstica pode diminuir a concentração bacteriana do leite "in natura" refrigerado, principalmente em relação a microrganismos patogênicos. O leite "in natura" armazenado em geladeira sem fervura prévia, por si só não é eficiente na diminuição da carga microbiana, pois favorece o crescimento bacteriano. O congelamento do leite diminui esse crescimento.

Durante o aquecimento, ocorreram perdas dos principais constituintes do leite (Gordura e Proteína) em algumas amostras. Estes resultados indicam necessidade de medidas que permitam obtenção de leite de melhor qualidade para a indústria e por conseqüência para o consumidor.

A estocagem do leite cru refrigerado, por períodos maiores que 48 horas é preocupante, pois reflete negativamente na qualidade do leite cru refrigerado.

Ficou evidente que as qualidades físico-químicas estão principalmente ligadas às práticas de manejo durante a ordenha.

\section{Agradecimentos}

Os autores do trabalho agradecem a FACEPE pelo suporte financeiro.

\begin{abstract}
The objective of this study was to evaluate the physical-chemical parameters of milk "in natura" marketed in the city of the Calçado - PE, in response to different temperatures. Samples were collected in small farms of Calçado - PE from august to December of 2009. The physical-chemical parameters had been evaluated after the samples to be submitted to the treatments: milk in natura to the ambient temperature (T1); after boil (T2); after refrigeration, $10^{\circ} \mathrm{C}$, for $48 \mathrm{~h}$ (T3) and after freezing for seven days (T4). The average values of density were below and above the recommended limits, in the different treatments. To the Dornic acidity, the values had exceeded the limit demanded by IN51. The milk "in natura", stored in refrigerator, favored the bacteria growth and the boil process provided reduction of the bacteria in the milk. It was demonstrated that the physical-chemistry quality are important to handling practical during milks production.
\end{abstract}


Key-words: Milk "in natura”, physical-chemical parameters, temperature.

\section{Referências}

ADAMS, D. M.; BARACH, J. T.; SPECK, M. L. Effect of psichrotrophic bacteria from raw milk on milk proteins and stability of milk proteins to ultrahigh temperature treatment. Journal of Dairy Science, v. 59, n. 6, p. 823-827, 1976. http://dx.doi.org/10.3168/jds.S0022-0302(76)84282-8

AGNESE, A. P. Avaliação físico-química do leite cru comercializado informalmente no município de Seropédica, Rio de Janeiro. Revista Higiene Alimentar, São Paulo, v. 17, n. 94, p. 58-61, 2002.

ALVIN, R. S. A.; MARTINS, P. C. Desafios nacionais para a cadeia produtiva de leite. In: VILELA, D.; BRESSAN, M.; FERNANDES, N. E.; ZOCCAL, R. ;MARTINS, C. M.; NOGUEIRA NETTO, V. (Eds.). Gestão ambiental e políticas para o agronegócio do leite. Juiz de Fora, MG: Embrapa Gado de Leite, 2003. p. 11-30.

BRANDÃO, A. S. P. Restrições econômicas e institucionais à produção de leite na Região Sul. In: RESTRIÇÕES TÉCNICAS, ECONÔMICAS E INSTITUCIONAIS AO DESENVOLVIMENTO DA CADEIA PRODUTIVA DO LEITE NO BRASIL - REGIÃO SUL, 1., 1999, Juiz de Fora, MG. Anais... Juiz de Fora: Embrapa Gado de Leite/MCT/CNPQ/PADCT, 1999. p. 27-34.

BRASIL. Ministério da Agricultura, Pecuária e Abastecimento. Instrução Normativa no. 051, de 18de setembro de 2002. Diário Oficial da União, Brasília, 20 set., Seção 1, p. 13-22. 2002.

DONATELE, D. M.; VIEIRA, L. F. P.; FOLLY, M. M. Relação do teste de Alizarol 72\% (v/) em leite "in natura" de vaca com acidez e contagem de células somáticas: Análise Microbiológica. Revista Higiene Alimentar, São Paulo, v. 17, n. 110, p. 95-100, 2003.

FAGAN, E. P.; BELOTI, V.; BARROS, M. A. F.; TAMANINI, R.; FAGNANI, R.; JOBIM, C. Avaliação de padrões físico químicos e microbiológicos do leite em diferentes fases de lactação nas estações do ano em granjas leiteiras no Estado do Paraná - Brasil. Semina: Ciências Agrárias, Londrina, v. 29, n. 3, p. 651-660, jul./set. 2008.

FONSECA, L. F. L.; SANTOS, M. V. Qualidade do leite e controle de mastite. São Paulo: Lemos, 2000.

FREITAS, J. A., SILVA, R. A. G., NASCIMENTO, J. A. C. Características do leite fluido consumido em Belém, Pará. Arquivo Brasileiro de Medicina Veterinária e Zootecnia, v. 47, n. 3, p. 435- 445, 1995.

FREITAS FILHO, J. R; FREITAS, W. R.; LIMA, R. S.; SILVA, M. S. J.; LIMA, R. T.; SOUZA, H. B.; LIMA, V. A. M. Avaliação do teor de caseína e albumina no leite de vacas da raça Girolanda. Revista Brasileira de Tecnologia Agroindustrial, v. 03, n. 01, 2009.

MARTINS, P. C.; YAMAGUCHI, L. C. T.; ARCURI, P. B.; ARCURI, E. F. O compromisso com a qualidade do leite no Brasil. In: Pagamento por qualidade no Brasil: motivações e obstáculos. Passo Fundo: UPF, 2004.

MATTOS, R. S. W.; PEDROSO, M. A. Influência da nutrição sobre a composição de sólidos totais no leite. In: SIMPÓSIO SOBRE BOVINOCULTURA LEITEIRA, 5., 2005, Piracicaba, SP. Anais... Piracicaba: FEALQ, 2005. p. 103-128.

MENDONÇA, A. H. et al. Qualidade físico-química de leite cru resfriado: comparação de diferentes procedimentos e locais de coleta. In: CONGRESSO NACIONAL DE LATICÍNIOS, 18., 2001, Juiz de Fora. Anais... Juiz de Fora: Templo. 2001. p. 276-282.

NERO, L. A.; MATTOS, M. R.; BELOTI, V.; BARROS, M. A. F.; PINTO, J. P. A. N.; ANDRADE, N. J.; SILVA, W. P.; FRANCO, B. D. G. M. Leite cru de quatro regiões leiteiras brasileiras: perspectivas de atendimento dos requisitos microbiológicos estabelecidos pela Instrução Normativa 51. Ciência e Tecnologia de Alimentos, v. 25, n. 1, p. 191195, 2005. http://dx.doi.org/10.1590/S0101-20612005000100031

OLIVEIRA, M. M. A. O.; NUNES, I. F. S. N.; ABREU, M. C. Análise microbiológica e físico-química do leite pasteurizado tipo C comercializado em Terezina, PI. Higiene Alimentar, São Paulo, v. 17, n. 111, p. 92-94, agosto, 2003.

PADILHA, M. R. F.; FERNADEZ, Z. F. Avaliação higiênico-sanitária do leite "C" comercializado no Recife - PE. Higiene Alimentar, São Paulo, v. 13, n. 61, p. 105-109, 1999. 
PEREIRA, C. S.; CONCEIÇÃO, J. V.; SILVA, H. M. Fatores ambientais e genéticos que afetam a produção de leite e gordura em vacas da raça holandesa. Arquivo Brasileiro de Medicina Veterinária e Zootecnia, v. 45, n. 1, p. 81-89, 1993.

PINTO, C. L. O.; MARTINS, M. L.; VANETTI, M. C. D. Qualidade microbiológica de leite cru refrigerado e isolamento de bactérias psicrotróficas proteolíticas. Ciência e Tecnologia de Alimentos, v. 26, n. 3, p. 645-651, 2006. http://dx.doi.org/10.1590/S0101-20612006000300025

POLEGATO, E. P. S.; RUDGE, A. C. Estudo das características físico-químicas e microbiológicas dos leites produzidos por mini-usinas da região de Marília - São Paulo/ Brasil. Revista Higiene Alimentar, São Paulo, v. 17, n. 110 , p. 56-63, 2003.

RODRIGUES, R.: FONSECA L. M.; SOUZA, M. R. Acidez do leite, Cadernos Técnicos da Escola Veterinária UFMG. n. 13, p. 63 - 72, 1995.

ROSSI, E. A.. O sistema lactoperoxidase na preservação de leite cru nas condições brasileiras. Dissertação de Doutorado. Campinas, Unicamp, 1992. 126p.

ROSSI, E. A.; OLIVEIRA, J. S.; FARIA, J. B.. Efeito da concentração de água oxigenada na eficiência do sistema lactoperoxidase ativado em leite. Ciência e Tecnologia de Alimentos, Campinas, v. 14, n. 2, p. 178-88, 1994.

SANTOS, E. C.; XAVIER, A. T. V.; PASSOS, L. A. S. Aparente deflexão sazonal de alguns constituintes do leite no início da primavera. Revista do Instituto de Laticínios Cândido Tostes, Juiz de Fora, v. 36, n. 215, p. 9-15, 1981.

SANTOS, P. A.; SILVA, M. A. P.; SOUZA, C. M.; ISEPON, J. S.; OLIVEIRA, A. N.; NICOLAU, E. S. Efeito do tempo e da temperatura de refrigeração no desenvolvimento de microrganismos psicrotróficos em leite cru refrigerado coletado na macrorregião de Goiânia, GO. Ciência Animal Brasileira, v. 10, n. 4, p. 1237-1245, out./dez. 2009.

SILVEIRA, N. V. V.; SAKUMA, H.; DUARTE, E. L. Avaliação das condições físico-químicas e microbiológicas do leite pasteurizado consumido na cidade de São Paulo. Revista do Instituto Adolfo Lutz, São Paulo, v. 49, n. 1, p. 19$22,1989$.

SOUZA, M. R., RODRIGUES, R., FONSECA, L. M., CERQUEIRA, M. M. O. P. Pasteurização do leite. Caderno Técnico da Escola de Veterinária UFMG, n. 13, p.85-93, 1995

TEIXEIRA, S.R. Pagamento pela Qualidade. In: BRITO, J.R.F.; DIAS, J.C. A Qualidade do Leite. EMBRAPA/TORTUGA,. p.51-58, 1998.

VIEIRA, T. R. L.; CARVALHO, M. G. X. Características microbiológicas e físico-químicas e condições higiênicosanitárias do leite pasteurizado tipo "C" comercializados na cidade de Patos - PB. In: CONGRESSO NACIONAL DE LATICÍNIOS, 20, 2003, Juiz de Fora. Anais... Juiz de Fora: Central Formulários, v. 58, n. 333, p. 201-203, 2003.

Submetido em 27 mar. 2010; Aceito para publicação em 24 out. 2011. 